\title{
Molecular Interactions and Binding Free Energy of Polydopamine and Methylene Blue: A DFT Study
}

\author{
Kunlanat SRIPHUMRAT ${ }^{\mathbf{1}}$, Phattaraporn THONGSAMAI ${ }^{1}$, Montra CHAIRAT ${ }^{\mathbf{1}}$, \\ Pilan SAENSUK ${ }^{1}$, Nawee KUNGWAN ${ }^{2,3}$ and Supaporn DOKMAISRIJAN ${ }^{1,2, *}$ \\ ${ }^{I}$ Division of Chemistry, School of Science, Walailak University, Nakhon Si Thammarat 80160, Thailand \\ ${ }^{2}$ Department of Chemistry, Faculty of Science, Chiang Mai University, Chiang Mai 50200, Thailand \\ ${ }^{3}$ Research Center on Chemistry for Development of Health Promoting Products from Northern \\ Resources, Chiang Mai University, Chiang Mai 50200, Thailand
}

('Corresponding author's e-mail: sdokmaisrijan@hotmail.com)

Received: 6 March 2019, Revised: 15 June 2019, Accepted: 10 July 2019

\begin{abstract}
Polydopamine (PDA) is a kind of mussel-inspired material. It has been applied as a coating and an adsorbent material. As an adsorbent, the PDA microspheres were used to remove methylene blue (MB) in aqueous solution. It was reported that the efficiency of the PDA adsorbent depends on the $\mathrm{pH}$ of the solution. Furthermore, in a $\mathrm{pH}$ range of 3 - 10, the hydroxyl and amine functional groups of PDA can be either protonated or deprotonated. The change of the net charge of PDA can affect the intermolecular interactions between PDA and MB. It was proposed that both of the electrostatic and $\pi-\pi$ interactions should be dominant in the acidic and basic solutions. Therefore, the structural properties and intermolecular interactions of the PDA-MB complex should be investigated. Such an investigation can be useful for the improvement of the PDA microspheres for the other dyes. To get insight into the roles of PDA structure and its role as an interesting adsorbent for MB, the PDA-MB complex formation was carried out at $\mathrm{pH}$ 7. The PDA dimers which have six possible structures were selected. The optimization of all PDA dimers and MB was performed in the gas phase at the B3LYP/6-311++G(d,p) calculations. After that, the complex formation of the optimized PDA dimers and MB was performed using the AutoDock Vina V1.1.2. The binding free energy of the PDA dimers and MB was in a range of -3.2 to -3.7 $\mathrm{kcal} / \mathrm{mol}$, which indicated that the binding of PDA dimer and MB is spontaneous. The results showed that the $\pi-\pi$ interaction between PDA dimer and MB plays a crucial role in the complex formation. Likewise, the sandwich-like structures of the complexes are more stable than the twisted structures.
\end{abstract}

Keywords: Polydopamine, Methylene blue, Binding free energy, DFT

\section{Introduction}

Polydopamine (PDA) becomes more interesting as a mussel-inspired material because it is responsible for adhesion to many kinds of surfaces [1-3]. PDA contains the catechol and nitrogencontaining groups and its synthesis is very simple and easy. Such a synthesis can be done by exposing dopamine (3,4-dihydroxyphenylethylamine) to air in alkaline solutions [4]. As a low-cost material, applications and adoptions of the PDA have been reported in many fields of science and applied engineering [1-11].

The PDA structure at the atomic level has not been reported since it is an amorphous solid. Thus, the Cartesian coordinates and structural parameters of the PDA should be investigated using a theoretical study. Lately, an $a b$ initio calculation of the molecular models of the PDA was proposed [12]. Many different structures of the PDA dimers, trimers, and tetramers were calculated at the B3LYP/def2-QZVP 
http://wjst.wu.ac.th

method [12]. For the PDA dimer, it was reported that six lowest-lying energy structures (A to F in Figure 1) of the PDA dimer were located in the B3LYP/def2-QZVP potential energy surface with relative structural energies in a range of $3.20 \mathrm{kcal} \mathrm{mol}^{-1}$ [12]. The structures of those six PDA dimers are unique since their C(ring)-C(ring) atom connection between each aromatic ring of each monomer is different [12]. As indicated in Chen et al. [12], dimerization of PDA from monomer units was made through the 2-, 4-, and 7-position [12]. Therefore, these six PDA dimers made through the 2,2'-, 2,4'-, 2,7'-, 4,4'-, 4,7'-, and 7,7'-position could be used as the smallest oligomers of PDA [12].<smiles>Oc1cc2cc(-c3cc4cc(O)c(O)cc4[nH]3)[nH]c2cc1O</smiles>

A<smiles>Oc1cc2[nH]ccc2c(-c2c(O)c(O)cc3cc[nH]c23)c1O</smiles>

D<smiles>Oc1cc2cc(-c3c(O)c(O)cc4[nH]ccc34)[nH]c2cc1O</smiles>

B<smiles>Oc1cc2cc(-c3c(O)c(O)cc4cc[nH]c34)[nH]c2cc1O</smiles>

$E$<smiles>Oc1cc2[nH]ccc2c([C]c2c(O)cc3[nH]ccc3c2O)c1O</smiles>

C

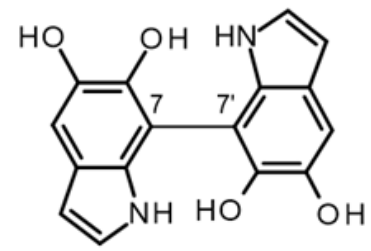

$\mathrm{F}$

Figure 1 Six most stable structures of the PDA dimer [12].

In a number of the study on the effectiveness of adsorption for dye removal from wastewaters using many kinds of agricultural waste, methylene blue (MB) has been selected as a model compound. This was done in order to evaluate the capability of adsorbent in removing dye from wastewaters [5-7,9]. The molecular structure of MB is shown in Figure 2. It should be noted that MB is a basic aniline dye and has important uses in both biology and chemistry [5-7,9]. For example, MB has been applied in many laboratories as an indicator and has been used as a cell straining for bacteria. Nonetheless, the removal of $\mathrm{MB}$ after use is very important because MB is a toxic substance [5-7,9].<smiles></smiles><smiles>CN(C)c1ccc2nc3ccc(=[N+](C)C)cc-3sc2c1</smiles>

Figure 2 The structure of MB.

As a coating and adsorbent material, the PDA microspheres were used as an adsorbent to remove $\mathrm{MB}$ in aqueous solution. For a study of MB removal using PDA [5], the researchers reported that the efficiency of the PDA adsorbent depends on the $\mathrm{pH}$ of the solution since the hydroxyl and amine functional groups of PDA can be either protonated or deprotonated. The MB molecule contains a positive charge so that the intermolecular interaction between PDA and MB could be affected directly from the 
http://wjst.wu.ac.th

net charge of PDA [5]. Furthermore, the electrostatic and $\pi-\pi$ interactions between PDA and MB should be more predominant in the acidic and basic solutions [5]. To get insight into the intermolecular interactions of PDA and MB, the structural properties and intermolecular interactions of the PDA-MB complex were focused in this study. The obtained information from this work can be useful for the improvement of the PDA microspheres for the other dyes.

This research aimed to examine the roles of PDA structure as an interesting adsorbent for MB. The PDA-MB complexes were carried out at $\mathrm{pH}$ 7. The six most stable structures of PDA dimer and an MB molecule (as shown in Figures 1 and 2, respectively) were applied to create the PDA-MB complexes using a docking technique. The docking results of the PDA-MB complexes and their binding free energies corresponding with their structures were analyzed and discussed.

\section{Materials and methods}

The six PDA dimers and an MB molecule were constructed as starting molecules for this theoretical study. The structural features of all PDA dimers and an MB molecule were mimic from those shown in Figures 1 and 2, respectively. The GaussView program V.5 was utilized to create those initial structures [13]. After that, all PDA dimers and MB were fully optimized in the gas phase at the B3LYP/6$311++\mathrm{G}(\mathrm{d}, \mathrm{p})$ calculations using Gaussian09 program package [14]. The net charge of each molecule of PDA dimer was zero while the net charge of $\mathrm{MB}$ was +1 . It should be noted that the conformational search of each PDA dimer was omitted since this study aimed to compare the stability order of the six reported PDA dimers. The optimized structures of all PDA dimers and an MB molecule were further used to construct the six PDA-MB complexes.

The predictions of plausible structures and binding free energies of each of PDA dimer and an MB molecule were performed using the AutoDock Vina (V.1.1.2) program, an open source program used for molecular docking [15]. This program has been applied for small protein-ligand docking and RNA-ligand docking. It was reported that the docking results compared to the crystallographic data are acceptable and reasonable since their coordinate root-mean-square displacements are very small. In this work, the possible binding sites of each PDA molecule were defined using the number of grid points in the $x-, y-$ and $\mathrm{z}$ - dimensions of 40, 40 and 40, respectively with spacing of $1.0 \AA$. The $\mathrm{x}-, \mathrm{y}$ - and $\mathrm{z}$-center of grid box are 0.0, 0.0 and 0.0, respectively. All parameters for the search technique were set as defaults of the program and the genetic algorithm was selected. The lowest binding energy pose structures of each PDAMB complex were selected and analyzed.

\section{Results and discussion}

The optimized structures of an MB molecule and the six PDA dimers

The three-dimensional structure of the optimized MB molecule has a planar skeleton and it is very similar to its two-dimensional structure as shown in Figure 2. Then, the optimized MB structure derived from the B3LYP/6-311++G(d,p) calculations was not shown.

The optimized structures of the six PDA dimers (the front view and the top view) with their relative structural energies $(\Delta \mathrm{E})$ are shown in Figure 3. 


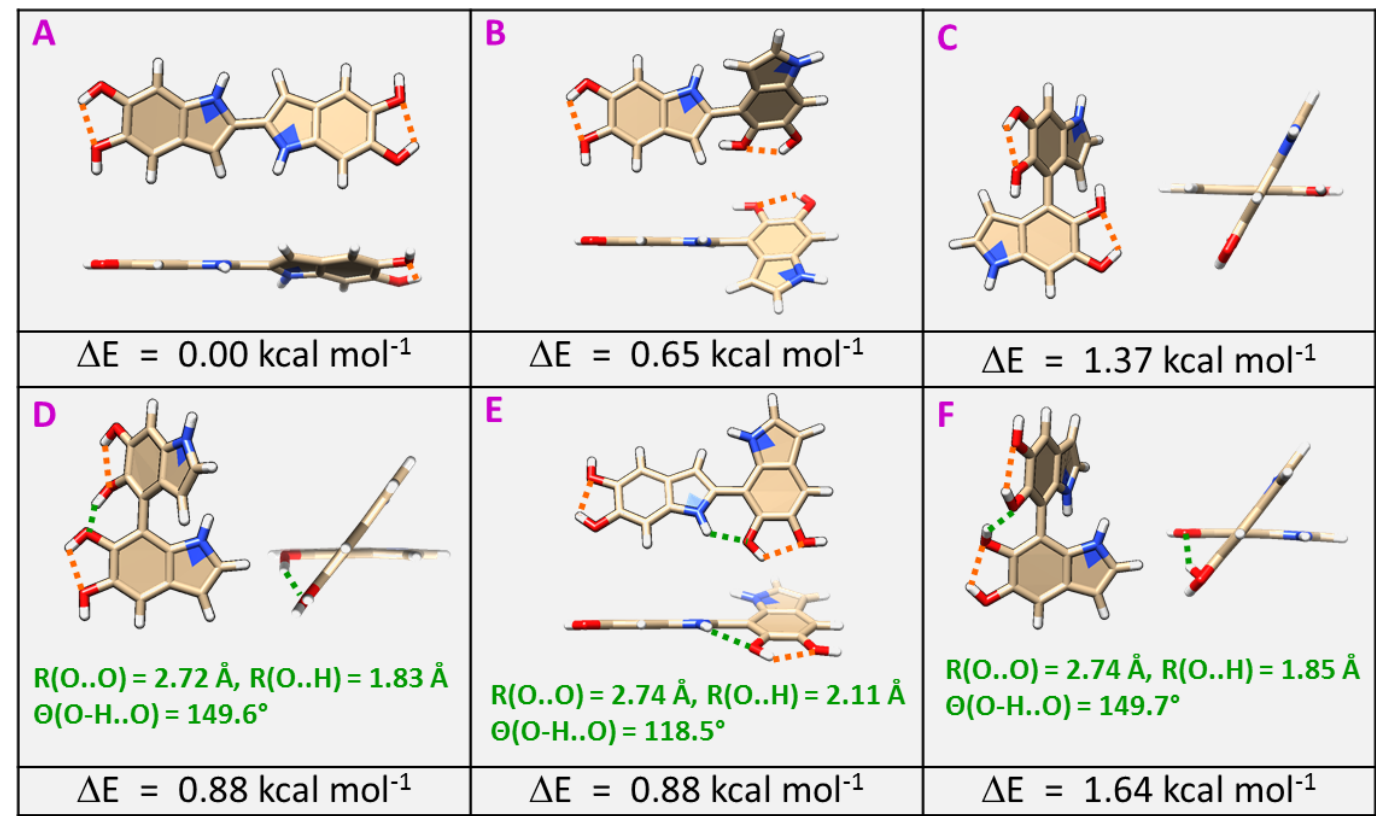

Figure 3 The optimized structures of the six PDA dimers obtained from the B3LYP/6-311++G(d,p) calculations.

Each optimized structure of the six PDA dimers had an intramolecular hydrogen bond (H-bond) between the catechol groups of each aromatic ring (shown as orange dash line in Figure 3). There was an intramolecular H-bond between two hydroxyl groups of each aromatic ring (shown as green dash line in Figure 3) found in the structures D, E and F. The structure A was the lowest energy structure and this was in good agreement with the reported information by Chen et al. [12]. The $\Delta \mathrm{E}$ values of $\mathrm{B}, \mathrm{D}$, and $\mathrm{E}$ indicated that the structures $\mathrm{B}, \mathrm{D}$, and $\mathrm{E}$ were higher in energy than the structure A, respectively. Compared to the structure $\mathrm{A}$, the structures $\mathrm{C}$ and $\mathrm{F}$ seemed to be two unstable structures (their $\Delta \mathrm{E}$ values are higher than $1 \mathrm{kcal} \mathrm{mol}^{-1}$ ).

From the calculations, the relative energies and stabilities of the PDA dimers A to F can have effects from the molecular planarity, conformation, intramolecular H-bond, and steric effect. The balance of those factors affects each PDA dimer in the different ways. Moreover, the number of intramolecular Hbond in a molecule cannot be used to evaluate the stabilities of PDA dimers and the strength of intramolecular $\mathrm{H}$-bond depends on the $\mathrm{H}$-bond distance and angle. The structure A has the nearly planar conformation and has no intramolecular H-bond between the hydroxyl groups of each aromatic ring. However, its $\Delta \mathrm{E}$ value was much lower than the others. The structure $\mathrm{B}$ was slightly more stable than structures D and E ( $0.23 \mathrm{kcal} \mathrm{mol}^{-1}$ higher than B), although the structures D and E had an intramolecular $\mathrm{H}$-bond between each aromatic ring (labeled as a green dash line). The structure B was little lower in energy than structure $\mathrm{E}$ because the structure $\mathrm{E}$ had steric effect from the $\mathrm{CH}$ (left ring) and $\mathrm{NH}$ (right ring), where its intramolecular H-bond was weak. For structures D and E having the same number of intramolecular $\mathrm{H}$-bond and with the same $\Delta \mathrm{E}$ values, the structure $\mathrm{D}$ was more twisted than structure $\mathrm{E}$. However, this had no steric effect. From the information of the intramolecular H-bond labeled as green dash line in Figure 3 of structures D and E, this intramolecular H-bond of structure D was stronger than that of structure E.

For the structures $\mathrm{C}$ and $\mathrm{D}$, which had a twisted conformation, the structure $\mathrm{D}$ was more stable than structure $\mathrm{C}\left(0.49 \mathrm{kcal} \mathrm{mol}^{-1}\right.$ higher than $\left.\mathrm{D}\right)$ due to the moderately strong intramolecular H-bond formation. For structures $\mathrm{C}$ and $\mathrm{F}$, the $\Delta \mathrm{E}$ value of structure $\mathrm{F}$ was slightly higher than that of structure $\mathrm{E}$ 
http://wjst.wu.ac.th

$\left(0.27 \mathrm{kcal} \mathrm{mol}^{-1}\right)$. It was found that structures $\mathrm{C}$ and $\mathrm{F}$ were considerably twisted, but the repulsion of structure $\mathrm{F}$ from the $\mathrm{NH}$ groups seemed to be more pronounced than the repulsion of the $\mathrm{OH}$ and $\mathrm{CH}$ groups of structure $\mathrm{C}$. Moreover, these energetic results revealed that the stability order of the six PDA structures differ from that reported by Chen et al. [12] which only had at the structures $\mathrm{C}, \mathrm{D}$, and E.

The structural and energetic results from this study suggested that the $\pi$-electron delocalization can have a major effect on the structural stability of the PDA dimer. This is due to the fact that the structure A is only one structure that has a planar skeleton. Likewise, its flat structure can promote the $\pi$-electron delocalization between its two aromatic rings.

\section{The six possible structures of the PDA-MB complexes}

The pose structure of each PDA-MB complex and its lowest binding free energy $\left(\Delta \mathrm{G}_{\text {binding }}\right)$ value are reported in Figure 4. The $\pi-\pi$ interactions between the aromatic rings are labeled in yellow lines.

All predicted PDA-MB complexes have negative $\Delta \mathrm{G}_{\text {binding }}$ values, indicating that all complexes can be formed. In other word, the binding of each PDA dimer and an MB molecule is a spontaneous process. The $\Delta \mathrm{G}_{\text {binding }}$ values of the six PDA-MB complexes are in a range of -3.2 to $-3.7 \mathrm{kcal} \mathrm{mol}^{-1}$, suggesting that the formation of the PDA-MB complex with the most negative $\Delta \mathrm{G}_{\text {binding }}$ value is more possible.

The PDA-MB complexes $\mathrm{A}$ and $\mathrm{E}$ have equal $\Delta \mathrm{G}_{\text {binding }}$ values $\left(-3.7 \mathrm{kcal} \mathrm{mol}^{-1}\right)$. These structures displayed that the skeleton of MB molecule is quite parallel with skeleton of the PDA dimer. Moreover, both of them showed that both aromatic rings of the PDA dimer can form the $\pi-\pi$ interactions with the thioninium ring of MB. For the PDA-MB complex B, its $\Delta G_{\text {binding }}$ value slightly increased $\left(-3.6 \mathrm{kcal}^{\mathrm{mol}}{ }^{-}\right.$ $\left.{ }^{1}\right)$ from that of the PDA-MB complexes A and E. The structure of the PDA-MB complex B presented that more than half molecule of MB can interact with the PDA dimer B while the rest of MB moved away from an aromatic ring of the PDA dimer B. The other PDA-MB complexes (C, D and F) can have the $\pi-\pi$ interactions but they are weaker than that of the PDA-MB complexes A and E. As can be seen in the PDA-MB complex $\mathrm{C}$, its $\Delta \mathrm{G}_{\text {binding }}$ value is equal to $-3.2 \mathrm{kcal} \mathrm{mol}^{-1}$. This PDA-MB complex $\mathrm{C}$ has the weakest $\pi-\pi$ interactions since only half molecule of the PDA dimer can interact with MB. In addition, other ring of the PDA dimer $\mathrm{C}$ is twisted and is turned away from the MB molecule. This resulted to the partial disruption of the $\pi-\pi$ interactions between the PDA dimer and MB molecule. 


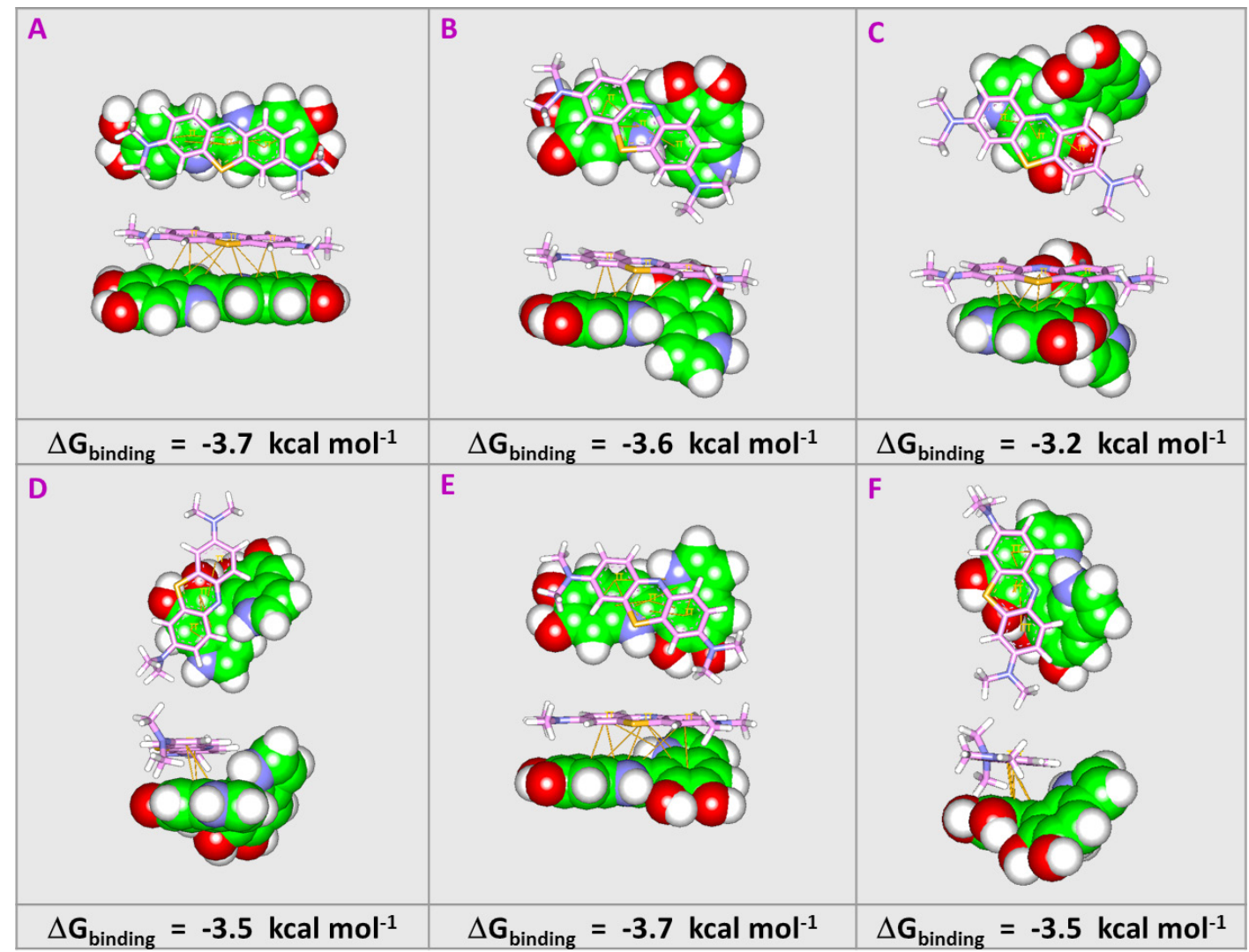

Figure 4 The lowest binding energy pose structures of the PDA-MB complexes derived from the docking.

\section{Conclusions}

The structural and energetic properties of the six PDA dimers and an MB molecule as well as those of the six PDA-MB complexes were investigated and analyzed. From the B3LYP calculations, the PDA dimer A was the most stable structure. The other PDA dimers (structures B to F) were less stable compared to the structure A. This can be explained that the nearly planar skeleton of the structure A can promote the $\pi$-electron delocalization between its two aromatic rings.

For the six predicted PDA-MB complexes obtained from the docking, the PDA-MB complexes A and $\mathrm{E}$ were most likely to be formed since they have the most negative $\Delta \mathrm{G}_{\text {binding }}$ values. The docking results revealed that the $\pi-\pi$ interaction between a PDA dimer and an MB molecule plays a crucial role in the complex formation. Furthermore, the parallel-like structures of the PDA-MB complexes are more stable than the twisted structures.

\section{Acknowledgements}

The authors would like to thank Walailak University for research facilities. K. Sriphumrat wishes to thank Walailak University for the IC4IR registration fee waiver. This research work was partially supported by Chiang Mai University. 
http://wjst.wu.ac.th

\section{References}

[1] CC Ho and SJ Ding. Structure, properties and applications of mussel-inspired polydopamine. $J$. Biomed. Nanotechnol. 2014; 10, 3063-84.

[2] J Liebscher, R Mrówczyński, HA Scheidt, C Filip, ND Hădade, R Turcu, A Bende and S Beck. Structure of polydopamine: A never-ending story? Langmuir 2013; 29, 10539-48.

[3] JH Ryu, PB Messersmith and H Lee. Polydopamine surface chemistry: A decade of discovery. ACS Appl. Mater. Inter. 2018; 10, 7523-40.

[4] YH Ding, M Floren and W Tan. Mussel-inspired polydopamine for bio-surface functionalization. Biosurf. Biotribol. 2016; 2, 121-36.

[5] J Fu, Z Chen, M Wang, S Liu, J Zhang, J Zhang, R Han and Q Xu. Adsorption of methylene blue by a high-efficiency adsorbent (polydopamine microspheres): Kinetics, isotherm, thermodynamics and mechanism analysis. Chem. Eng. J. 2015; 259, 53-61.

[6] VK Garg, M Amita, R Kumar and R Gupta. Basic dye (methylene blue) removal from simulated wastewater by adsorption using Indian Rosewood sawdust: a timber industry waste. Dyes. Pigments 2004; 63, 243-50.

[7] BH Hameed, ATM Din and AL Ahmad. Adsorption of methylene blue onto bamboo-based activated carbon: Kinetics and equilibrium studies. J. Hazard. Mater. 2007; 141, 819-25.

[8] M Rafatullah, O Sulaiman, R Hashim and A Ahmad. Adsorption of methylene blue on low-cost adsorbents: A review. J. Hazard. Mater. 2010; 177, 70-80.

[9] V Vadivelan and KV Kumar. Equilibrium, kinetics, mechanism, and process design for the sorption of methylene blue onto rice husk. J. Colloid. Interf. Sci. 2005; 286, 90-100.

[10] F Yu, S Chen, Y Chen, H Li, L Yang, Y Chen and Y Yin. Experimental and theoretical analysis of polymerization reaction process on the polydopamine membranes and its corrosion protection properties for 304 Stainless Steel. J. Mol. Struct. 2010; 982, 152-61.

[11] J Zhou, B Duan, Z Fang, J Song, C Wang, PB Messersmith and H Duan. Interfacial assembly of mussel-inspired Au@Ag@ polydopamine core-shell nanoparticles for recyclable nanocatalysts. Adv. Mater. 2014; 26, 701-5.

[12] CT Chen, FJ Martin-Martinez, GS Jung and MJ Buehler. Polydopamine and eumelanin molecular structures investigated with ab initio calculations. Chem. Sci. 2017; 8, 1631-41.

[13] R Dennington, T Keith and J Millam. GaussView05. Semichem, Shawnee Mission, 2009.

[14] MJ Frisch, GW Trucks, HB Schlegel, GE Scuseria, MA Robb, JR Cheeseman, G Scalmani, V Barone, B Mennucci, GA Petersson, H Nakatsuji, M Caricato, X Li, HP Hratchian, AF Izmaylov, J Bloino, G Zheng, JL Sonnenberg, M Hada, M Ehara, K Toyota, R Fukuda, J Hasegawa, M Ishida, T Nakajima, Y Honda, O Kitao, H Nakai, T Vreven, JA Montgomery, Jr., JE Peralta, F Ogliaro, M Bearpark, JJ Heyd, E Brothers, KN Kudin, VN Staroverov, R Kobayashi, J Normand, K Raghavachari, A Rendell, JC Burant, SS Iyengar, J Tomasi, M Cossi, N Rega, JM Millam, M Klene, JE Knox, JB Cross, V Bakken, C Adamo, J Jaramillo, R Gomperts, RE Stratmann, O Yazyev, AJ Austin, R Cammi, C Pomelli, JW Ochterski, RL Martin, K Morokuma, VG Zakrzewski, GA Voth, P Salvador, JJ Dannenberg, S Dapprich, AD Daniels, Ö Farkas, JB Foresman, JV Ortiz, J Cioslowski and DJ Fox. Gaussian 09, Revision E.01. Wallingford, CT, 2009.

[15] O Trott and AJ Olson. AutoDock Vina: Improving the speed and accuracy of docking with a new scoring function, efficient optimization, and multithreading. J. Comput. Chem. 2010; 31, 455-61. 